\title{
FATIGUE LIFE PREDICTION OF COMMERCIALLY PURE TITANIUM AFTER NITROGEN ION IMPLANTATION
}

\author{
Nurdin Ali $^{1,2}$, M.S. Mustapa ${ }^{1}$, M.I. Ghazali ${ }^{1}$, T. Sujitno ${ }^{3}$ and M. Ridha ${ }^{2}$ \\ ${ }^{1}$ Faculty of Mechanical and Manufacturing Engineering \\ Universiti Tun Hussein Onn Malaysia, 86400 Parit Raja - Batu Pahat, Malaysia \\ Email: nurdinali_usk@yahoo.com \\ ${ }^{2}$ Department of Mechanical Engineering, Faculty of Engineering \\ Syiah Kuala University, Banda Aceh 23111, Indonesia \\ ${ }^{3}$ National Nuclear Energy Agency, Yogyakata 55281, Indonesia
}

\begin{abstract}
Prediction of fatigue life has become an interesting issue in biomaterial engineering and design for reliability and quality purposes, particularly for biometallic material with modified surfaces. Commercially pure titanium ( $\mathrm{Cp}$-Ti) implanted with nitrogen ions is a potential metallic biomaterial of the future. The effect of nitrogen ion implantation on fatigue behavior of $\mathrm{Cp}-\mathrm{Ti}$ was investigated by means of axial loading conditions. The as-received and nitrogen-ion implanted specimens with the energy of $100 \mathrm{keV}$ and dose of $2 \times 10^{17}$ ions $\mathrm{cm}^{-2}$, were used to determine the fatigue properties and to predict the life cycle of the specimens. The effect of nitrogen ion implantation indicated revealed improved the tensile strength due to the formation of nitride phases, $\mathrm{TiN}$ and $\mathrm{Ti}_{2} \mathrm{~N}$. The fatigue strength of Cp-Ti and Nii-Ti was 250 and $260 \mathrm{MPa}$, respectively. The analytical results show good agreement with experimental results.
\end{abstract}

Keywords: Cp-Ti; fatigue; fatigue life; biomaterial; ion implantation.

\section{INTRODUCTION}

In addition to the design of joint replacements, the material selected plays a very important role. Materials for human body implants must be biocompatible, corrosion resistant, strong, and display adequate elasticity (Pompe et al., 2004). Titanium meets these requirements to a very high degree; it has excellent temperature stability, wear and abrasion resistance, and is lightweight (Qu et al., 2005, Kustas and Misra, 1992). The use of titanium alloy Ti-6Al-4V in preference to pure titanium in biomedical applications is because of its superior mechanical properties and moderate modulus, i.e., 100-110 GPa (Elias et al., 2008). However, the drawback of this alloy is that corrodes to some extent in body fluids, thereby releasing ions that might possibly be harmful over a prolonged period. It is now believed that aluminium ions have been associated with Alzheimer's disease and V, Co, Mo, $\mathrm{Ni}$, and $\mathrm{Cr}$ ions are suspected of being toxic or carcinogenic (Rogers et al., 1997). Therefore, pure titanium is considered a better solution because it will not produce toxic ions and its mechanical properties satisfy biomedical application requirements (Silvaa et al., 2004). Titanium has excellent corrosion resistance, good biocompatibility, and a good specific strength-to-weight ratio, but poor wear resistance. If it were utilized as a metal-to-metal artificial hip replacement, in which wear resistance is property of interest, surface modification of $\mathrm{Cp}$-Ti would be necessary in order in to improve its surface wear properties. 
Surface modification methods, such as anodic oxidation treatment, sandblasting, carbide coating, plasma nitriding, electrochemical treatment, and nitrogen ion implantation (Velten et al., 2002; Kapczinski et al., 2003; Guilherme et al., 2005; Jagielski et al., 2006; Jiang et al., 2006; Song et al., 2007; Ali et al., 2011), have been proposed to increase the corrosion resistance and wear resistance of the material. The technique of nitrogen ion implantation has been explained well and shown to be a good method by which to enhance passivity and to reduce corrosion rate. This is due to the formation of $\mathrm{TiN}$ and $\mathrm{Ti}_{2} \mathrm{~N}$ phases, which avoids the migration of ions and stabilizes the $\mathrm{TiO}_{2}$ film growth on the surface of Cp-Ti (Arenas et al., 2000). Nitrogen ion implantation modifies the $\mathrm{Cp}$-Ti surface to produce wear resistant species like nitrides ( $T i N ; \mathrm{Ti}_{2} \mathrm{~N}$ ) other than $\mathrm{TiO}_{2}$ on the surface. The ion implantation technique is now available as an industrial-scale process that allows medical engineering to improve hardness, corrosion resistance, and achieve an accuracy of form necessary for biomedical devices. Additionally, the ion implantation technique is also employed to enhance fatigue properties for some critical components. A detailed explanation of the ion implantation process is given by Nastasi and Mayer (2006).

Almost all of the surface treatment processes, including ion implantation, are prone to roughness and contamination because surface voids can cause an increasing risk of the modified surface being susceptible to corrosion. Electrochemical investigations of the corrosion behavior of $\mathrm{Cp}$ - $\mathrm{Ti}$ and titanium alloys have almost always demonstrated a very good passivity condition of the surface. However, studies focusing on ensuring the reliability of medical implants are still insufficient. Therefore, the fatigue life prediction of pure titanium as an implant material, following nitrogen ion implantation, will be a valuable contribution to ensuring the sustainability of the implanted devices. The objectives of this study are to evaluate the fatigue properties of the $\mathrm{Cp}$-Ti implanted with nitrogen ions and to predict the fatigue life time of the $\mathrm{Cp}-\mathrm{Ti}$ implanted with nitrogen ions (Nii-Ti), based on experimental data.

\section{MATERIAL AND METHODS}

The material used in this study was $\mathrm{Cp}$ - $\mathrm{Ti}$ in the form of a round 30-mm-diameter bar, originally supplied by Fiko Ltd., Ukraine with the code of VT1-0 grade. The chemical composition and mechanical properties of the investigated material are listed in Tables 1 and 2. The microstructure of the $\mathrm{Cp}-\mathrm{Ti}$ in original condition (as-received $\mathrm{Cp}$ - $\mathrm{Ti}$ ) is shown in Figure 1.

Table 1. Chemical composition of original Cp-Ti.

\begin{tabular}{ccccccccc}
\hline $\mathrm{N}$ & $\mathrm{C}$ & $\mathrm{H}$ & $\mathrm{Fe}$ & $\mathrm{O}$ & $\mathrm{Al}$ & $\mathrm{Si}$ & $\mathrm{Ti}$ & $\mathrm{Res}$ \\
\hline 0.04 & 0.05 & 0.003 & 0.13 & 0.11 & 0.49 & 0.03 & base & 0.30 \\
\hline
\end{tabular}

Table 2. Mechanical properties of original $\mathrm{Cp}$-Ti.

\begin{tabular}{cccc}
\hline $\begin{array}{c}\text { Ultimate Tensile } \\
\text { Strength }(\mathrm{MPa})\end{array}$ & $\begin{array}{c}\text { Elongation } \\
(\%)\end{array}$ & $\begin{array}{c}\text { Reduction Area } \\
(\%)\end{array}$ & $\begin{array}{c}\text { Impact } \\
\text { Strength }\end{array}$ \\
\hline 430 & 29 & 56 & 16 \\
\hline
\end{tabular}




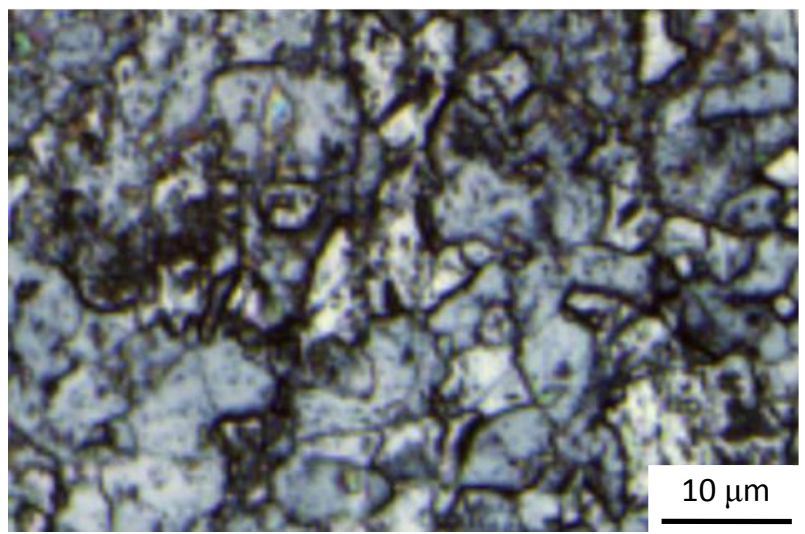

Figure 1. Microstructure of original Cp-Ti, etching of $10 \% \mathrm{HF}$ and $5 \% \mathrm{HNO}_{3} ; 200 \times$ (Falazzaky et al., 2012).

Fatigue specimens are prepared based on ASTM E466 and E 468. Firstly, Cp-Ti was prepared in lengths of $90 \mathrm{~mm}$, and then cut in to four parts by using a wire-cutting machine. Secondly, the machining processes were carried out to form the standard specimens by using an automatic lathe. Finally, the specimens were ground with abrasive paper and then polished by using $1 \mu \mathrm{m}$ diamond paste to achieve surface roughness values of $0.06-0.1 \mu \mathrm{m}$. Fatigue tests were performed on specimens with the shape and dimensions shown in Figure 2. Polished specimens were rinsed with water, and then ultrasonically cleaned with ethanol over 30 minutes and dried at room temperature prior to the nitrogen ion implantation process. They are subjected to implantation of nitrogen ions with the energy of $100 \mathrm{keV}$ and dose of $2 \times 10^{17}$ ions cm${ }^{-2}$, which were reported as the optimum parameters by Fulazzaky et al. (2012).

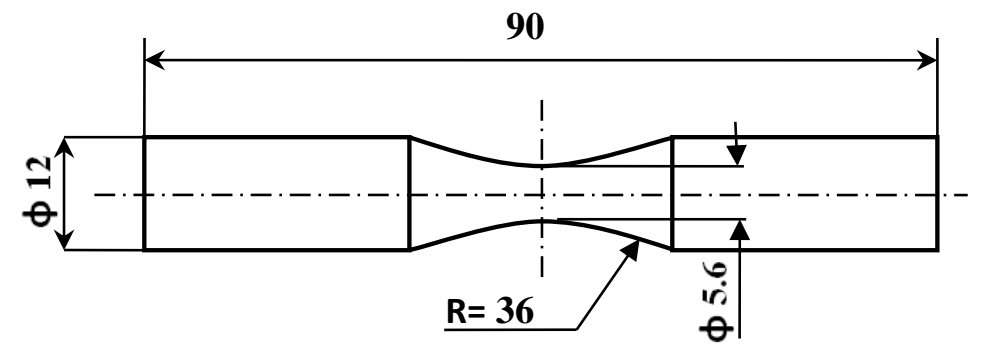

Figure 2. Shape and dimensions of the fatigue specimen $(\mathrm{mm})$.

\section{RESULTS AND DISCUSSION}

\section{Nitride Phases and Tensile Properties}

Preliminary studies on the mechanical properties show that nitrogen ion implantation improves the tensile properties, wear resistance, and corrosion behavior (Fulazzaky et al., 2012). Results of the tensile test exhibit an improvement of tensile properties of $\mathrm{Cp}$-Ti following nitrogen ion implantation, as shown in Table 3. The improvement of those properties was due to the formation of a new phase in the $\mathrm{Cp}$-Ti system called titanium nitride, e.g., $T i N$ and $T i_{2} N$. X-ray diffraction (XRD) observations exhibited that these phases have the unit cell of fcc $(\mathrm{TiN})$ and tetragonal $\left(\mathrm{Ti}_{2} \mathrm{~N}\right)$, whereas 
the $\mathrm{Cp}$-Ti itself has a hexagonally spaced lattice. Figure 3 shows the XRD pattern of Nii-Ti. The combination of phases of $\mathrm{Ti}, \mathrm{TiN}$ and $\mathrm{Ti}_{2} \mathrm{~N}$ in the subsurface of $\mathrm{Cp}$-Ti, following implantation with nitrogen ions, enhances the surface strength, wear and pretting resistance, and introduces positive changes to the ductility.

Table 3. Tensile properties of original Cp-Ti and Nii-Ti.

\begin{tabular}{lccc}
\hline \multicolumn{1}{c}{ Measurement } & Unit & $\mathrm{Cp}-\mathrm{Ti}$ & $\mathrm{Nii}-\mathrm{Ti}$ \\
\hline Ultimate tensile strength & $\mathrm{MPa}$ & 497 & 539 \\
0.2\% offset yield strength & $\mathrm{MPa}$ & 385 & 440 \\
Elongation in 25 mm & $\%$ & 33.3 & 36.6 \\
\hline
\end{tabular}

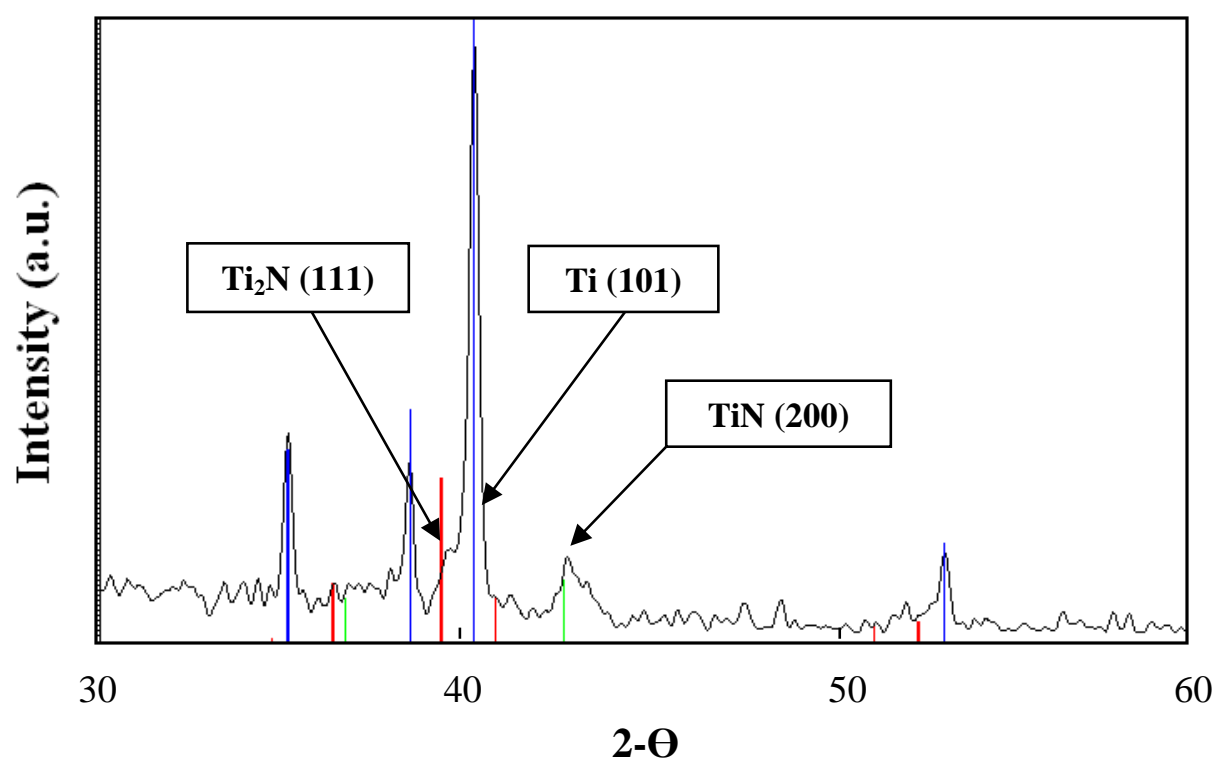

Figure 3. XRD pattern of Nii-Ti implanted with energy of $100 \mathrm{keV}$ and dose of $2 \times 1017$ ions $\mathrm{cm}^{-2}$.

As reported by $\mathrm{Yu}$ et al. (1993), the corrosion fatigue (C-F) endurance of Ti$6 \mathrm{Al}-4 \mathrm{~V}$ was also increased effectively by nitrogen ion implantation. Because this material is prepared for hip joint replacement applications, the fatigue behavior as well as $\mathrm{CF}$ of Nii-Ti is also expected to be better than $\mathrm{Cp}-\mathrm{Ti}$.

\section{Stress-life (S-N) Curves}

Fatigue can be defined as the sequential stages of metal damage that evolve with accumulated load cycling in a laboratory environment. Material loaded cyclically below its yield stress will also fail following a specific number of cycles. An aggressive environment can lower the fatigue life of a material significantly, which is known as corrosion-fatigue. Figure 4 shows S-N curves for $\mathrm{Cp}$-Ti and Nii-Ti determined in this work and compared with the work of Fleck and Eifler (2010). The graph shows that the endurance of $\mathrm{Cp}$-Ti and Nii-Ti in the current study is at the stress of 250 and $260 \mathrm{MPa}$, respectively, with $1 \times 10^{7}$ cycles. It is verified that the fatigue test program in the present work could be fatigued by a stress of 250-320 MPa. 


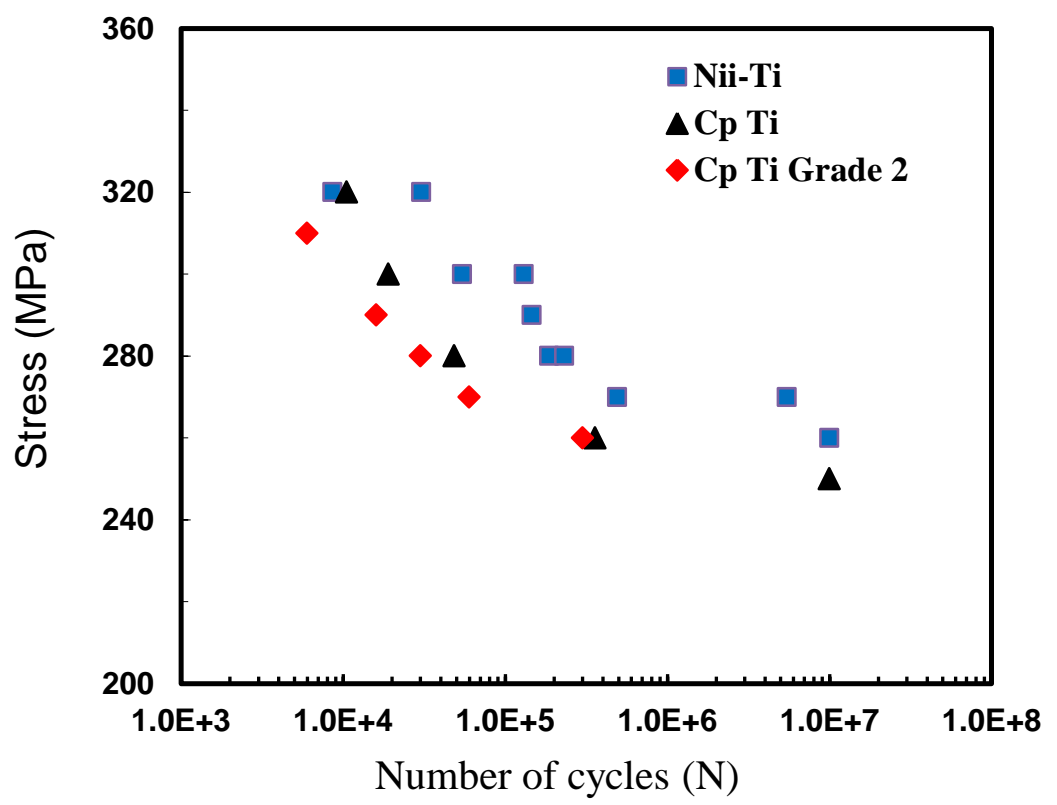

Figure 4. S-N curves of Cp-Ti and Nii-Ti compared with Cp-Ti Grade 2 (Fleck and Eifler, 2010).

\section{Prediction of Fatigue Life}

Fatigue failure occurs when the material experiences cyclic stresses and strains that produce permanent damage. Two major components of the crack phase will occur during the fatigue failure process: the initiation, and the propagation of fatigue cracks under cycling load (Xiang et al., 2010; Domínguez Almaraz et al., 2010; Kamal et al., 2012; Zulkifli et al, 2011). The summation of these components in number of cycles is called the fatigue life, and the stress or strain under which the fatigue life occurs is defined as the fatigue strength. Fatigue life prediction for $\mathrm{Cp}$-Ti following ion implantation is needed for the design and reliability of surgical implants. Two methodologies are available for the prediction of fatigue life: one based on the material stress-life curve (Figure 4) or strain-life, and a damage accumulation model, based on the fracture mechanics and crack growth analysis approach. The second method of fatigue life prediction is used to calculate the number of cycles for failure of a component by taking into account the equivalent initial flaw size (EIFS). The basic equation for calculating the EIFS using a short crack has been proposed by several researchers (El Haddad et al., 1979; Xiang et al., 2010). The equation expresses the fatigue endurance $\Delta \sigma_{f}$ by using the fatigue threshold stress intensity factor $\Delta K_{t h}$, crack length $a$, and a geometry correction factor $Y=0.73$, which is crack configuration dependent (Nan et al., 2008):

$$
\Delta K_{t h}=K_{t} \sigma_{f} \sqrt{\pi a} Y
$$

where $K_{t}$ is the stress concentration factor specimen $K_{t}=1.04$ (Nan et al., 2010). The crack length can be estimated from Eq. (1) as follows: 


$$
a_{c}=1 / \pi\left(\frac{\Delta K_{t h}}{K_{t} \sigma_{f} Y}\right)^{2}
$$

An empirically assumed crack length, such $0.25-1 \mathrm{~mm}$ for metal (Liu and Mahadevan, 2009) can also be considered in solving the problem of life prediction based on fracture mechanics. Substituting those values obtained from Eqs. (1) and (2) into Paris's equation, the fatigue crack growth of a material can be expressed as follows:

$$
\frac{d a}{d N}=C\left(\Delta K_{t h}\right)^{\mathrm{m}}
$$

By integration of the fatigue crack growth (Eq. 3) for the entire cycle of the performed fatigue life, Eq. (3) can be rewritten as:

$$
\int_{0}^{N} d N=\int_{a_{i}}^{a_{c}} \frac{1}{C\left(\Delta K_{t h}\right)^{\mathrm{m}}} d a
$$

where $C, m$, and $\Delta K_{t h}$ are material constants of fitting parameters. The constants $C$ and $m$ for pure titanium with a yield tensile strength of $380 \mathrm{MPa}$ are $1.95 \times 10^{-11}$ and 3.41 (Carpinteri and Paggi, 2007), respectively. Fatigue life of each stress level could be predicted using Eq. 5. Figure 5 shows the S-N curves of the experimental and analytical results for Nii-Ti.

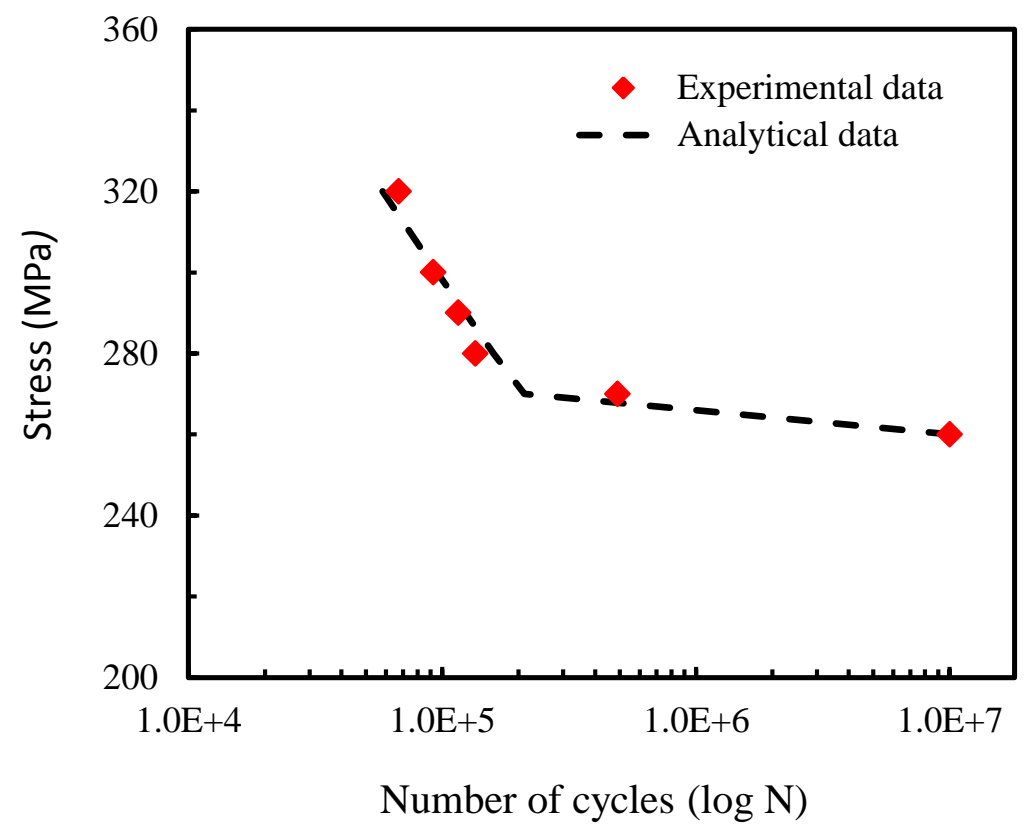

Figure 5. S-N curves of experimental and analytical results for Nii-Ti.

The experimental data used to construct the graph was the averaged value of experimental results under the assumption that both the analytical and the experimental results have the fatigue endurance of $260 \mathrm{MPa}$ with the number of cycles of $10^{7}$. The graph (Figure 5) shows the goodness-of-fit result of the analytical prediction and experimental observation, particularly at high stress levels. For lower stress levels, slightly over the fatigue limit, the fatigue life of the analytical result is lower than the experimental results. This is because of the use of Paris's constant for pure titanium. 
Further study is required to determine the Paris's constant for nitrogen-ion implanted Cp-Ti.

\section{CONCLUSIONS}

The effect of nitrogen ion implantation indicates an improvement in the tensile strength due to the formation of nitride phases, $\mathrm{TiN}$ and $\mathrm{Ti}_{2} \mathrm{~N}$. The fatigue strength of $\mathrm{Cp}$-Ti and Nii-Ti was 250 and $260 \mathrm{MPa}$, respectively. The analytical results were validated by using the average value of the experimental results of Nii-Ti. The analytical results show good agreement with the experimental results. However, the new model of fatigue life prediction needs further study.

\section{ACKNOWLEDGMENTS}

The authors gratefully acknowledge financial support from the Ministry of Science, Technology and Innovation, Malaysia (MOSTI) under fund Science Fund Project Vote No. S015

\section{REFERENCES}

Ali, N., Samekto, H., Ghazali, M.I. and Ridha, M. 2011. Surface modification of pure titanium by nitrogen ion at different beam energy and dose. Key Engineering Materials, 462-463: 750-755.

Arenas, M.A., Tate, T.J., Conde, A. and De Damborenea, J. 2000. Corrosion behaviour of nitrogen implanted Titanium in simulated body fluid. British Corrosion Journal, 35(3): 1-5.

Carpinteri, A. and Paggi, M. 2007. Self-similarity and crack growth instability in the correlation between the Paris' constants. Engineering Fracture Mechanics, 74: 1041-1053.

Domínguez Almaraz, G.M., Guzmán Tapia, M., Tapia Silva, E.E. and Cadenas Calderón, E. 2010. Fatigue life prediction based on macroscopic plastic zone on fracture surface of AISI-SAE 1018 steel. International Journal of Automotive and Mechanical Engineering, 1: 29-37.

El Haddad, M.H., Topper, T.H. and Smith, K.N. 1979. Prediction of non-propagation crack. Engineering Fracture Mechanics, 11(3): 573-584.

Elias, C.N., Lima, J.H.C., Valiev, R. and. Meyers, M.A. 2008. Biomedical applications of titanium and its alloys. Biological Materials Science, JOM: 46-49.

Fleck, C. and Eifler, D. 2010. Corrosion, fatigue and corrosion fatigue behaviour of metal implant materials, especially titanium alloys. International Journal of Fatigue, 32: 929-935.

Fulazzaky, M.A., Ali, N., Samekto H. and Ghazali, M.I. 2012. Assessment of Cp-Ti surface properties after nitrogen ion implantation with various doses and energies. Metallurgical and Materials Transactions, 43A: 4185-4193.

Guilherme, A.S., Henriques, G.E., Zavanelli, R.A. and Mesquita M.F. 2005. Surface roughness and fatigue performance of commerciallypure titanium and Ti-6Al$4 \mathrm{~V}$ alloy after different polishing protocols. Journal of Prosthetic Dentistry, 93(4): 378-385. 
Jagielski, J., Piatkowska, A., Aubert, P., Thome, L., Turos, A. and Abdul Kader, A. 2006. Ion implantation for surface modification of biomaterials. Surface and Coatings Technology, 200(22-23): 6355-6361.

Jiang, X.P. Wang, X.Y, Li, J.X., Man, C.S, Shepard, M.J. and Zhai, T. 2006. Enhancement of fatigue and corrosion properties of pure Ti by sandblasting. Materials Science and Engineering A, 429: 30-35.

Kamal, M., Rahman, M.M. and Rahman, A.G.A. 2012. Fatigue life evaluation of suspension knuckle using multi body simulation technique. Journal of Mechanical Engineering and Sciences, 3: 291-300.

Kapczinski, M.P., Gil, C., Kinast, E.J. and Alberto dos Santos, C. 2003. Surface modification of titanium by plasma nitriding. Materials Research, 6(2): 265-271.

Kustas, F.M. and Misra, M.S. 1992. Friction and wear of titanium alloys. in: ASM Handbook, Friction, Lubrication, and Wear Technology. ASM International, pp. 778-784.

Liu, Y. and Mahadevan, S. 2009. Probabilistics fatigue life prediction using an equivalent initial flaw size distribution. International Journal of Fatigue, 31: 476-487.

Nan, Z.Y., Ishihara, S. and Goshima, T. 2008. Corrosion fatigue behaviour of extruded magnesium alloy AZ31 in sodium chloride solution. International Journal of Fatigue, 30: 1181-1188.

Nastasi, M. and Mayer, J.W. 2006. Ion implantation and synthesis of materials. Berlin, German: Springer.

Pompe, W. Worch H., Epple M., Friess W., Gelinsky, M. and Greil, P. 2004. Functionally graded materials for biomedical applications. Materials Science and Engineering A, 362: 40-60.

Qu, J., Blaua, P.J., Watkinsa, T.R., Cavinb, O.B. and Kulkarni, N.S. 2005. Friction and wear of titanium alloys sliding against metal, polymer and ceramic counterfaces. Wear, 258: 1348-1356.

Rogers, S.D., Howie, D.W. Graves, S.E., Pearcy, M.J. and Haynes, D.R. 1997. In vitro human monocyte response to wear particles of titanium alloy containing vanadium or niobium. Journal of Bone Joint Surgery (Br), 79(B): 311-315.

Silvaa, H.M., Schneiderb, S.G. and Moura Neto, C. 2004. Study of nontoxic aluminium and vanadium-free titanium alloys for biomedical applications. Materials Science and Engineering C, 24: 679-682

Song, H.J., Kim, M.K., Jung, G.C., Vang, M.S. and Park, Y.J. 2007. The effect of spark anodizing treatment of pure titanium metals and titanium alloys on corrosion characteristics. Surface and Coating Technology, 201: 8738-8745.

Velten, D., Biehl, V., Aubertin, F., Valeske, B., Possart, W. and Breme, J. 2002. Preparation of $\mathrm{TiO} 2$ layers on $\mathrm{cp}-\mathrm{Ti}$ and $\mathrm{Ti} 6 \mathrm{Al} 4 \mathrm{~V}$ by thermal and anodic oxidation and by sol-gel coating techniques and their characterization. Journal of Biomedical Materials Research A, 59(1): 18-28.

Xiang, Y., Lu, Z. and Liu, Y. 2010. Crack growth-based fatigue life prediction using an equivalent initial flaw model. Part I: Uniaxial loading. International Journal of Fatigue, 32(2): 341-349.

Yu, J., Zhao, Z.J. and Li, L.X. 1993. Corrosion fatigue resistances of surgical implant stainless steel and titanium alloy. Corrosion Science, 35(1-4): 587-597.

Zulkifli, A., Ariffin, A.K. and Rahman, M.M. 2011. Probabilistic finite element analysis on vertebra lumbar spine under hyperextension loading. 3: 256-264. 
Ali et al. /International Journal of Automotive and Mechanical Engineering 7(2013) 1005-1013 